\title{
LEIDEN ASIA YEAR 2017: SYMPOSIA, WORKSHOPS EN TENTOONSTELLINGEN IN HET KADER VAN AZIË
}

Op I4 september 2017 vindt de feestelijke opening plaats van de Asian Library van de Universiteit Leiden. De Asian Library brengt alle Aziëcollecties van de Universitaire Bibliotheken Leiden samen en is ondergebracht in een nieuwe verdieping die boven op de Universiteitsbibliotheek is gebouwd. De opening van dit nieuwe expertisecentrum is de aanleiding voor het Leiden Asia Year 2017.

Gedurende het hele jaar staan de universiteit en de stad in het teken van Azië, met als doel om Leiden nog eens extra op de kaart te zetten als kenniscentrum voor Azië. De Leidse universiteit staat bekend als een van de oudste en meest gerenommeerde centra in het Westen voor de studie van de talen en culturen van Azië. De collecties van de universiteit en van instellingen zoals de Hortus Botanicus, het Japan Museum Sieboldhuis en het Museum Volkenkunde zijn eveneens wereldwijd vermaard. Ze omvatten zeldzame manuscripten, kaarten, kunstvoorwerpen en andere materialen, zoals de planten die Philipp Franz von Siebold (I796-I866)

TITII

Leiden Asia Year

Kom in 2017 naar Leiden!

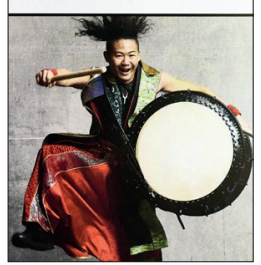

Afb. 1 Japanse drummers, optreden in de Stadsgehoorzaal Leiden, 10 mei 2017 verzamelde in Japan. Deze collecties en de banden van de universiteit met Azië worden belicht in een jaar vol Azië-activiteiten.

Enkele hoogtepunten uit het programma zijn het symposium Collecting Asia in maart dat zich richt op de geschiedenis van het verzamelen van Aziatische objecten in Leiden. In mei en juni zal een serie lezingen getiteld Imagine Asia Today huidige trends in film, kunst, literatuur en muziek uit Azië bespreken. Eind juni bekijkt het symposium Knowing Asia hoe Leidse Aziatische collecties hebben bijgedragen aan ideeën over Azië. In het Leids Academisch Kunstcentrum (LAK) worden in maart en november workshops georganiseerd in onder andere Indonesische dans, Chinese kalligrafie en Japanse dichtkunst. Ook zal de app Walking with Indonesia voor mobiele telefoon en tablet beschikbaar worden gemaakt. Hiermee kunnen bezoekers een wandeling maken langs plekken in de stad die met Indonesië te maken hebben. Tijdens de openingsweek van de nieuwe bibliotheek van II tot en met I7 september zijn er extra veel activiteiten, zoals de vertoning van drie korte films van het CinemaAsia Film Festival op I4 september in de filmzaal van de Asian Library.

In de loop van het jaar zijn verschillende tentoonstellingen te bezichtigen. Hieronder volgt een kleine selectie. In het Museum Volkenkunde is Schatten uit het Depot: Indonesische Bronzen te zien (6 juli $2016 \mathrm{t} / \mathrm{m}$ 30 juni 2019). Deze tentoonstelling laat voor het eerst meer dan 200 Indonesische beelden en rituele voorwerpen uit de periode tussen de $8^{\mathrm{e}}$ en $15^{\mathrm{e}}$ eeuw zien. Ook is in het Museum Volkenkunde Cool Japan te zien (I4 april t/m i7 september). Cool Japan gaațin op de fascinatie vopror Japan $02: 57: 57 \mathrm{pm}$ 
en de populaire Japanse beeldcultuur van manga, Hello Kitty en robots. In de Universiteitsbibliotheek wordt de tentoonstelling A Buddha in the Back Yard: Asia as a Source of Inspiration gehouden over boeken, films en voorwerpen uit Azië en hun herinterpretatie in Europa (26 januari t/m $8 \mathrm{mei}$ ). Ook is daar Cultural Dynamics of Sanskrit te zien (I8 mei t/m 29 augustus). Door middel van manuscripten, foto's en video's wordt getoond hoe belangrijk het Sanskriet is geweest voor de verspreiding van ideeën, verhalen en beelden in Azië.

\footnotetext{
Afb. 2

Tentoonstelling

Cultural Dynamics of Sanskrit, UB Leiden, vanaf 18 mei 2017
}

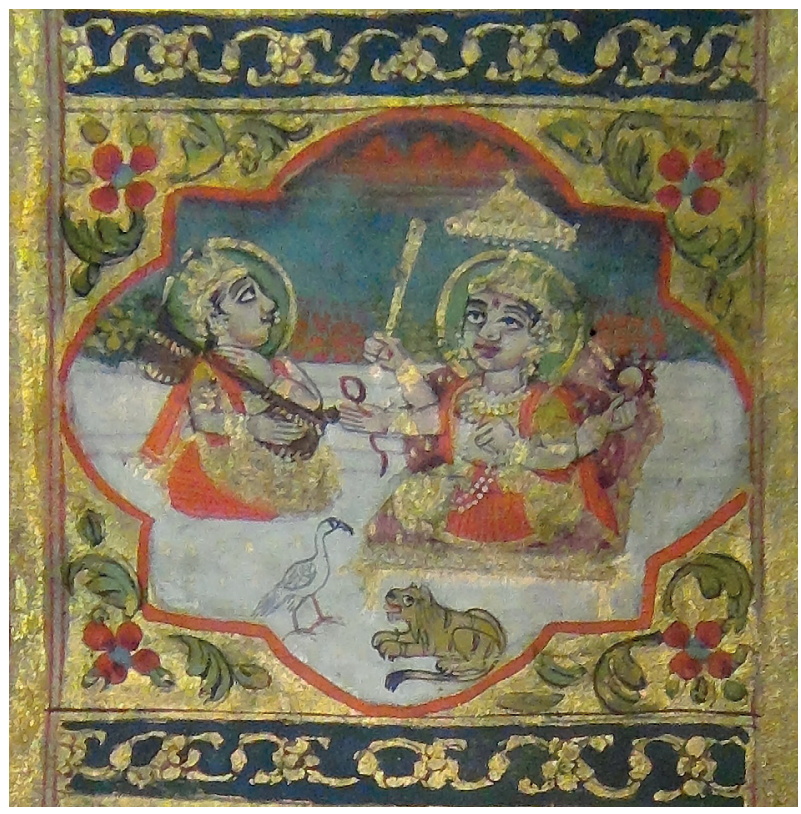

In de Hortus Botanicus belicht de tentoonstelling Kroonjuwelen uit Azië de bijzondere relatie tussen de botanische tuin in Bogor op Java en de Indonesische collectie van de Hortus (I4 april t/m 8 oktober). Bezoekers ontvangen een boekje met recepten met kruiden uit Azië.

Evenementen uit het reguliere programma van de universiteit, zoals de Dies Natalis op 8 februari en de opening van het academisch jaar op 4 september staan eveneens in het teken van Azië. Meer informatie en de laatste versie van het programma zijn te vinden op: www.leidenasiayear.nl

- Paramita Paul is sinologe. Na haar promotie heeft zij aan de Universiteit Leiden en op het Leiden University College in Den Haag lesgegeven. Momenteel werkt zij bij Amsterdam University College. 


\section{Uniqueness meets perfection}

\section{Steltman Jade Collection}

A pair of earrings set with green moonstones, diamonds and jade carvings.


ATELIER - JEWELRY - WATCHES 


\section{GUUS RÖELL FINE ART}

Tel.: 0653211649 | e-mail: g.roell@xs4all.nl | website: www.guusroell.com Tongersestraat 2, $6211 \mathrm{LN}$ Maastricht

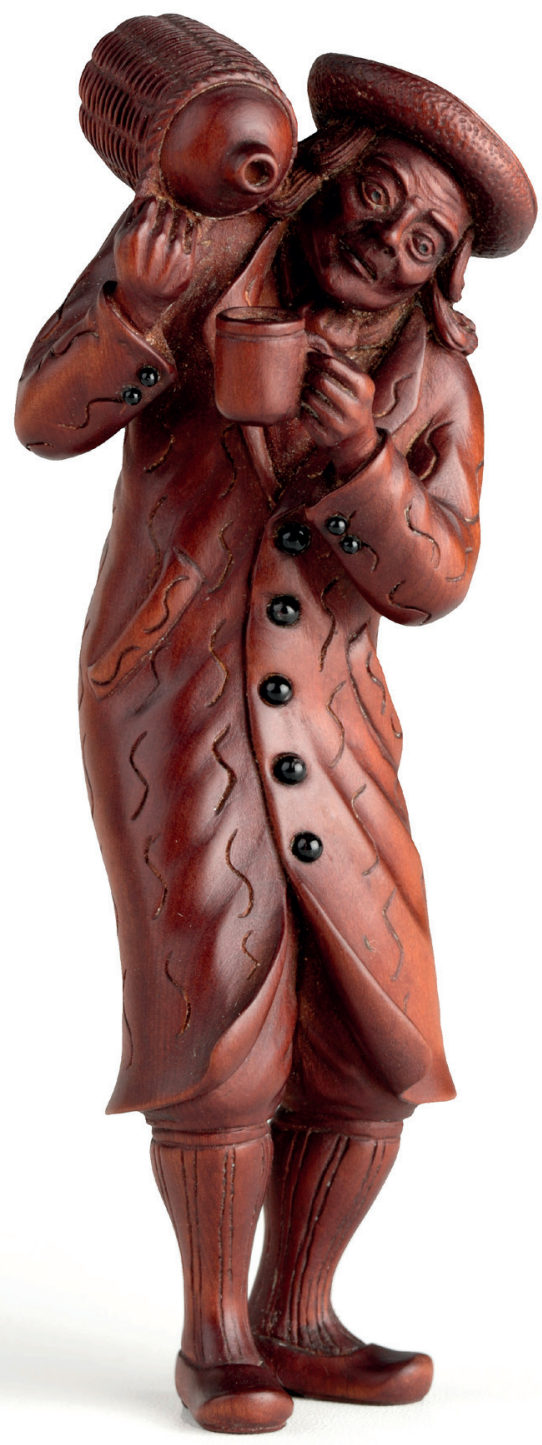

Akira Kawahara (geb. 1934). Netsuke van een Hollander die wijn in een beker schenkt. Palmhout met inleg van ebbenhout. Hoogte II cm. 


\section{MARCEL NIES ORIENTAL ART}

Lange Gasthuisstraat 282000 Antwerpen België marcelnies@skynet.be

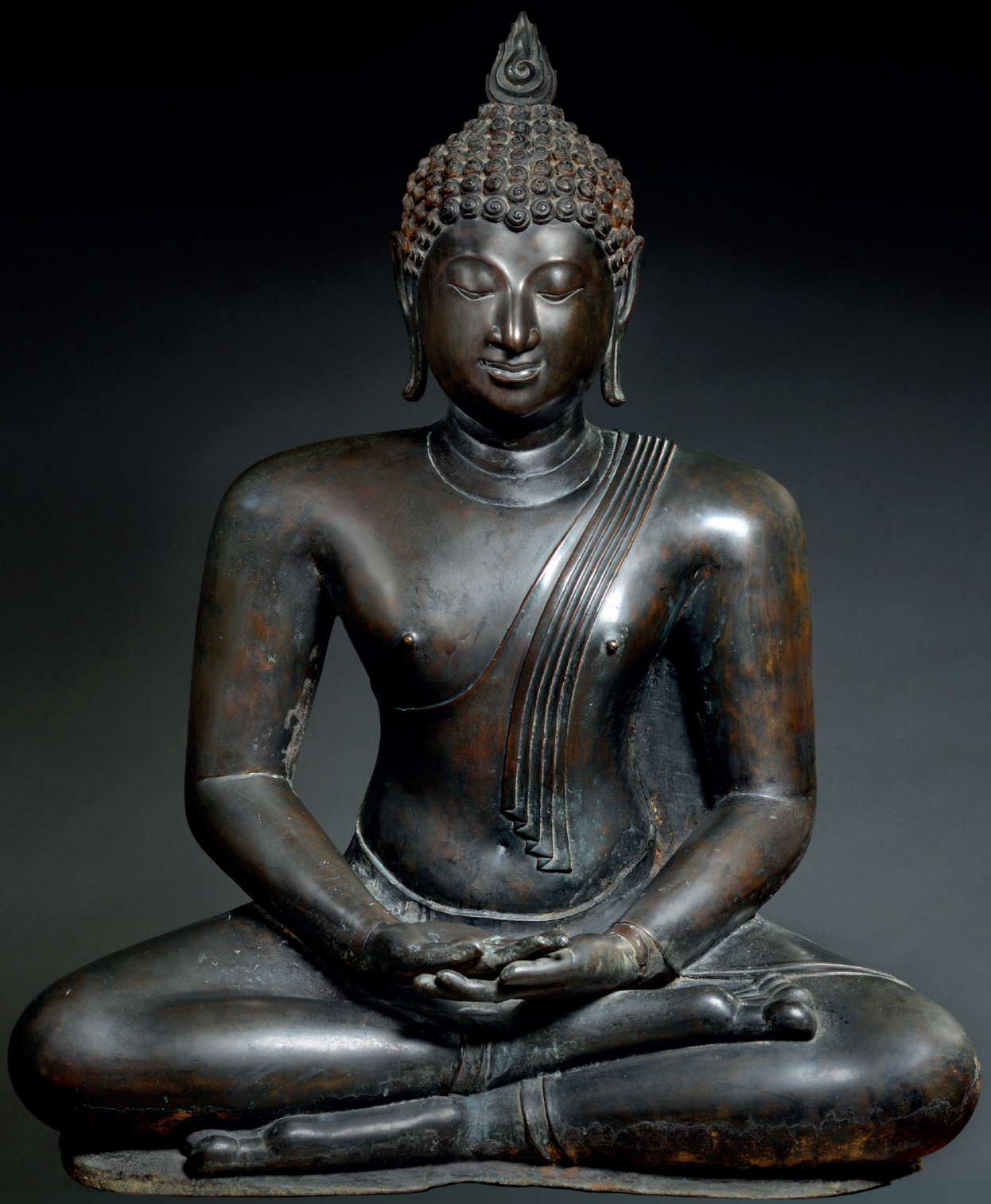


www.patergratiaorientalart.com

Patêr Gratia Oriental Art? Specialized in fine Chinese and Japanese 17 th and 18th century Export Porcellain (2) 


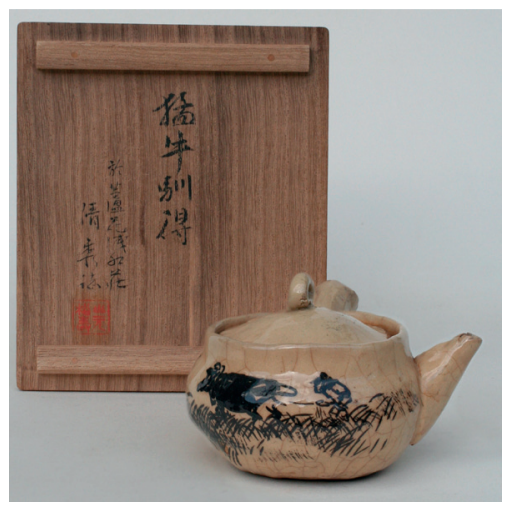

Yamamoto Shunkyo (187I-1933), Zezeyaki

Kyûsu, theepotje - Môgŷ̂ tokujun, domesticated fierce bull gesigneerd: Shunkyo met kâ̂ en zezeyaki zegel

Bruin gecraqueleerd Zezeyaki aardenwerk met een tetsu-e, ijzeroxide onderglazuurschildering. afmetingen: $\varnothing 8 \times 7$ (I2 X IO X 7).

De kist is geautoriseerd door zijn zoon Yamamoto Kiyohide.

Vanwege deze inscriptie op de kist betekent het dat dit theepotje heeft behoord tot de inventaris van Shunkyo's atelier.

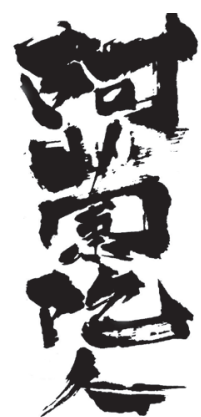

\section{ORANDA JIN}

Japanese paintings \& painters' pottery

Kalverstraat 28

$5223 \mathrm{AD}$ 's-Hertogenbosch

tel: +31 (0)73-621 8951

e-mail: orandajin@home.nl www.orandajin.com (nieuwe update eerste week van de maand)

\section{Frides Laméris}

\section{KUNST- EN ANTIEKHANDEL VOF}

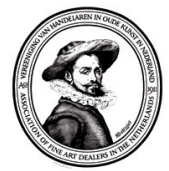

Nieuwe Spiegelstraat 55 IoI7 DD Amsterdam Telefoon 020-6264066 info@frideslameris.nl www.frideslameris.nl glas - ceramiek objets de collection

Een Chine de Commande bord met een liefdespaar en in de verte een Nederlands schip.

China, Jindezhen. Midden I8de eeuw. $\varnothing_{22,5} \mathrm{~cm}$

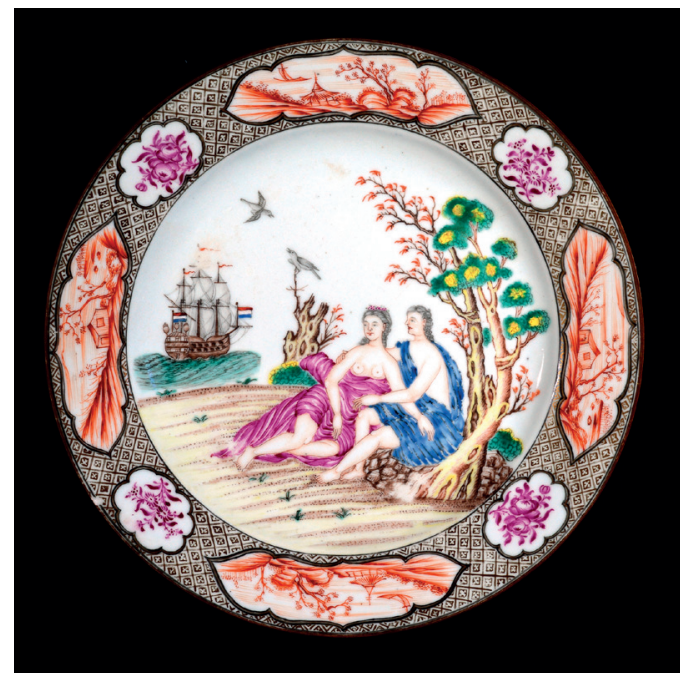




\section{AstamangalA}

OUDE KUNST UIT TIBET, NEPAL EN INDIA

KEIZERSGRACHT 574 • 1017 EM AMSTERDAM (SPIEGELKWARTIER)

TEL: 020-6234402 • E-MAIL: ASTA@XS4ALL.NL • WWW.ASTAMANGALA.COM



thangka van Yamantaka yab-yum

verf op textiel

Tibet, 19de eeuw, afm.: $101 \times 79 \mathrm{~cm}$. 